\title{
A Multi-Country BVAR Model for the External Sector ${ }^{1}$
}

Olga Korotkikh, Bank of Russia

spiridonovaoa@mail.cbr.ru

This paper describes a multi-country BVAR model developed and used by the Monetary Policy Department of the Bank of Russia. The model makes it possible to build coordinated scenario forecasts for the main macro-variables of the USA, the euro area, and China. The simultaneous modelling for the three economies makes it possible to take into account multi-country interactions of the variables and, thus, improve the predictive performance of the model compared to VAR analogues intended for individual countries. The model is based on the deviations of the variables from their potential values, which enhances GDP growth forecasts compared to a non-detrended design. A wide range of macroeconomic and financial indicators in the model makes the forecast of overall inflation more accurate against simpler benchmarks.

Keywords: multi-country model, Bayesian methods, conditional forecasting, VAR model

JEL Codes: $G 21, G 28$
Citation: Korotkikh, O. (2020). A MultyCountry BVAR Model for the External Sector. Russian Journal of Money and Finance, 79(4), pp. 98-112.

doi: $10.31477 /$ rjmf.202004.98

\section{Introduction}

The Bank of Russia's Monetary Policy Department (MPD) currently uses a multi-country Bayesian vector autoregression (BVAR) model to build scenario forecasts for the main macroeconomic indicators of the external sector. The BVAR model for the external sector simultaneously models the economies of the USA, the euro area, and China, collectively making up 45\% of the global GDP and driving the world economy. The purpose of building the model is to obtain coordinated scenario forecasts for the external sector. Scenarios rely on assumptions regarding the movements of the US dollar index and the future paths of oil prices and policy rates. In other words, the model predicts the co-movements of a wide range of variables for the three economies conditionally, based on particular scenario assumptions. As a result, a fairly broad picture of the economic situation in foreign markets under various scenarios is obtained.

\footnotetext{
${ }^{1}$ I would like to express my gratitude to the former employees of the Bank of Russia who took part in the development of the model, namely Olga Borzykh, Nikita Kulagin, and Yury Perevezentsev.
} 
The key model variables are GDP growth and overall inflation. GDP growth rates are used to additionally calculate output gaps for the USA and the euro area and model the global GDP forecast. The forecasts obtained are further used as assumptions for a medium-term forecast in the quarterly projection model (QPM) and the dynamic stochastic general equilibrium (DSGE) for Russia.

The external sector BVAR model consists of 46 macroeconomic and financial variables. The incorporation of additional macroeconomic and financial indicators in the model in addition to the key variables improves the forecast of overall inflation compared with simpler VAR benchmarks.

The variables used in the model were taken in deviations from their potential values. The paths of potential values for key variables were estimated using auxiliary models, namely the multivariate filter described by Benes et al. (2010) and the model suggested by Holston et al. (2017) for neutral rates. As a result, we obtained the economically justified and coordinated paths of potential values for the main variables. The model-based approach to finding potential levels helps promptly adjust the results depending on the current situation, which enhances the flexibility of scenarios used in forecasting. The detrended design of the external sector BVAR model ensures the convergence of forecast paths to potential levels, thus improving the accuracy of the GDP growth forecast in comparison with the classic nondetrended design.

The simultaneous modelling of the three economies within a single VAR approach makes it possible to generate a forecast that takes into account the complex structure of intra-country and multi-country interactions of a large number of variables. As a result, this enhances the forecast accuracy compared to vector autoregression (VAR) models intended for individual countries.

This research relies on quarterly data beginning from 1996Q2. However, the incorporation of a large number of variables and their lags in the model involves the problem of overparameterisation, which is relevant for many macroeconomic VAR models characterised by a low frequency. To address the problem of overparameterisation, the VAR model is estimated using the Bayesian approach. The model parameters are reduced using the Minnesota prior distribution proposed by Doan et al. (1984) and Litterman (1986).

The choice of a multi-country BVAR as the main approach to modelling the external sector is based on the intent to build consistent forecasts simultaneously for a large number of variables for the three major economies. However, the simultaneous usage of a large number of variables for several countries makes it difficult to impose structural restrictions on model parameters. This was the reason why the VAR approach was chosen. VAR models do not require any additional structural restrictions to be imposed on model parameters and make it possible to generate an overall forecast that would take into account the complex structure of intra-country and multi-country effects of a large number of variables on each other.

The problem of overparameterisation in VAR models can be solved in several ways that are most often described in the literature. The easiest way is to reduce 
the dimensionality of the model by excluding variables. However, this approach may cause a bias in estimates because of the omission of a significant variable. For example, Christiano et al. (1999) demonstrate that when forward-looking variables, e.g. commodity prices, are left out of models, this may quite often entail the so-called price puzzle in VAR models, that is, a situation where inflation rises in response to monetary policy tightening. Moreover, when the dimensionality is reduced, VAR models lose their key advantage - the possibility to generate coordinated forecasts for a large number of variables simultaneously.

Alternative methods for solving the problem of overparameterisation are much more common in the literature. One of the popular approaches for panel VAR models is the global vector autoregressive (GVAR) model proposed by Pesaran et al. (2004).

GVAR models comprise two stages. At the first stage, small VAR models are estimated for each country. In these models, the influence of all other countries is factored in as a single exogenous variable of the global average. At the second stage, individual VAR models are combined and estimated within a single system. Owing to their design, GVAR models are most extensively employed for modelling closed economic systems. For this reason, a GVAR model generally comprises a large number of countries, i.e. more than ten, at the same time (the use of GVAR models was described in detail by di Mauro and Pesaran, 2013).

The most common and flexible alternative for dealing with the overparameterisation problem is the Bayesian VAR model (BVAR) estimation. BVAR solves the problem of excessive parameterisation by imposing prior restrictions on model parameters. Under the frequentist (non-Bayesian) approach, random variables are the estimators of model parameters, while in Bayesian econometrics random variables are model parameters themselves. Bayesian estimators combine prior distributions and data. In the case of structural models, a large number of parameters conveying multi-country effects are subject to a tight restriction, 'the coefficient is equal to zero'. By using prior distributions, it is possible to set a similar restriction in a milder form as 'the coefficients are centred at zero but have a small non-zero variance'. Thus, multi-country effects are not excluded completely (for details, refer to Del Negro and Schorfheide, 2011).

It should be noted that all the above approaches have their own relative advantages and should complement rather than substitute each other. We opt for BVAR as the most flexible approach that requires no additional ad hoc assumptions and may be used without any restrictions for unbalanced panel data. Moreover, large BVAR models have a high predictive accuracy. Bańbura et al. (2010) carried out a general study of the predictive performance of BVAR models based on the US macro data. The authors compare BVAR models with different dimensionalities, concluding that the accuracy of forecasts and impulse responses increases if, in addition to the key variables (consumer price index (CPI), policy rate, unemployment), the model also incorporates additional variables, such as real income, real consumption, financial indices, industrial production indices, and additional price indicators. At the same 
time, BVAR models comprising about 20 basic variables achieve the same accuracy as models with 130 variables that include additional sectoral indicators. Thus, by incorporating additional price, financial, and macroeconomic indicators in the model, it is possible to enhance the predictive accuracy of a BVAR model for the key variables.

The BVAR approach to predicting the co-movements of variables for several countries is widely applied by other central banks and international organisations. In addition to its basic structural model COMPASS, the Bank of England uses a BVAR analogue. According to Domit et al. (2016), the forecasts of GDP and its components in the BVAR model are more accurate than those in COMPASS, while inflation forecasts have the same accuracy. The European Central Bank (ECB) employs BVAR models for the four largest EU economies to forecast GDP and inflation (Angelini et al., 2019) and to analyse the effect of quantitative easing (Lenza and Slacalek, 2018). The Bundesbank uses a BVAR model to analyse the impact of ECB monetary policy shocks on the four major EU economies (Mandler et al., 2016). According to Capolongo and Pacella (2019) from the Bank of Italy, an inflation forecast generated by a large-scale BVAR model for the EU is more accurate than that prepared using separate models for each country.

Further on, the paper is organised as follows. Section 2 describes the data used in the model and the algorithms for their transformation. Section 3 describes the external sector BVAR model: the parameter estimation methodology, the hyperparameter selection algorithm, and the conditional forecasting algorithm. Section 4 provides a comparative analysis of the predictive capabilities of the external sector BVAR model. Section 5 illustrates how the BVAR model is employed by the Bank of Russia using the example of a joint forecasting round in December 2019.

\section{Variables of the external sector BVAR model}

The external sector BVAR model comprises 46 variables. Additionally, the potential levels of each indicator are estimated. All variables in the model are taken in deviations from their potential levels. The first part of this section describes the data used in the model, specifying the sources and required transformations. The second part describes the methodology for estimating the equilibrium paths for each variable.

\subsection{Data}

The BVAR model for the external sector relies on the following groups of variables observed simultaneously for China, the euro area, and the USA: real GDP, real GDP components (consumption, investment, imports, exports, and government expenditures), unemployment, CPI, core CPI, indices of export and import 
prices, GDP deflator, stock indices, and indices of business activity (PMI and others). In addition to the above groups of variables, the model also incorporates the US dollar index and the nominal Brent oil price. Thus, there are a total of 46 variables employed, 45 of which are endogenous variables of the model, and the Brent price is set as an exogenous variable. The model is quarterly and covers the period from 1996Q2 to the current available observation. The list of all variables, specifying their sources, is provided in the Appendix (see Table 4). The data collected are transformed according to the following algorithm:

- If the original data series is not seasonally adjusted (SA), the X-13-ARIMASEATS adjustment algorithm is applied.

- All data are converted into quarterly frequency. For monthly and daily data, the quarterly average is used.

- All variables are taken in deviations from their potential values. For percentage variables and PMI, the deviation of a variable from its potential is used. For the data series expressed as rates, the deviation of the first difference of logarithms (growth rates) from potential growth rates is used.

According to Carriero et al. (2015), when a model is specified in growth rates, this enhances the predictive performance of such models despite the fact that this approach does not take into account possible long-term relationships between variables.

The use of detrended series ensures the stationarity of all series and the subsequent stability of the model. The results of checking the model for unit roots are provided in the Appendix (see Figure 3). The figure shows that all eigenvalues are inside the unit circle. In addition, the detrended design allows a gradual convergence of forecasts to their potential levels that are initially set and adjusted depending on scenario assumptions and the current global situation. This improves the predictive performance of the model. ${ }^{2}$

\subsection{Potential values of variables}

All model variables are set in deviations from their potential values which are put into the same form as the observed variables. The equilibrium levels of GDP and unemployment are estimated using the model employed by the International Monetary Fund (IMF) (Benes et al., 2010). Target inflation is used as the equilibrium inflation rate, which is also in line with the model described by Benes et al. (2010). Neutral interest rates are estimated using the model suggested by Holston et al. (2017), where the results from the model proposed by Benes et al. (2010) are used as potential GDP growth rates affecting the neutral rate. This makes it possible to obtain the consistent and economically justified paths of potentials for key model variables. Given the large number of variables, it is quite

\footnotetext{
2 The comparison of the mean normalised root-mean-square error (MNRMSE) for the BVAR model in the detrended and restored forms is given in Section 4.2, Table 3.
} 
difficult to apply a single economically justified model-based approach to finding the potential levels of all variables; therefore, for the remaining variables, standard approaches are employed to detrend these series. The methodology for finding the equilibrium paths for the groups of variables is provided in Table 1.

Table 1. Methodology for estimating the equilibrium values of variables in the external sector BVAR model

\begin{tabular}{|c|c|}
\hline Group of variables & Methodology \\
\hline Potential GDP growth rates & Multivariate filter proposed by Benes et al. (2010) \\
\hline Potential growth rates of GDP components & According to formula (1) \\
\hline Potential unemployment rate & Multivariate filter proposed by Benes et al. (2010) \\
\hline $\begin{array}{l}\text { Equilibrium growth rates of CPI, core CPI, } \\
\text { and GDP deflator }\end{array}$ & Target inflation \\
\hline $\begin{array}{l}\text { Equilibrium values of growth rates of export/ } \\
\text { import price indices }\end{array}$ & Hodrick-Prescott filter for the first difference of logarithms \\
\hline $\begin{array}{l}\text { Equilibrium values of growth rates } \\
\text { of stock indices }\end{array}$ & Hodrick-Prescott filter for the first difference of logarithms \\
\hline Neutral policy rate & Model proposed by Holston et al. (2017) \\
\hline Equilibrium values of DXY growth rates & Assumption of zero quarterly growth rates in a steady state \\
\hline $\begin{array}{l}\text { Equilibrium growth rates of economic activity } \\
\text { indices }\end{array}$ & Hodrick-Prescott filter for the first difference of logarithms \\
\hline Equilibrium PMI & Autoregressive distributed lag model ARDL (2) \\
\hline Equilibrium oil price growth rates & $\begin{array}{l}\text { Based on the BVAR model for the oil price } \\
\text { developed by the MPD }\end{array}$ \\
\hline
\end{tabular}

The potential growth rates of GDP components were calculated according to the following formula:

$$
C_{j i t}^{*}=\left(\frac{G D P_{i t}^{*} \operatorname{Share}_{j i t}^{*}}{G D P_{i t-1}^{*} \operatorname{Share}_{j i t-1}^{*}}-1\right) \times 100,
$$

where $C_{j i t}^{*}$ is the potential growth rates of the component $j \in$ [private consumption; government expenditures; imports; exports; and investment] of the country $i \in$ [the USA; the euro area; China] for the period $t, G D P_{i t}$ is the potential GDP of the country $i$ for the period $t$; and Share ${ }_{j i t}$ is the share of the component $j$ in the GDP of the country $i$ for the period $t$ measured through filtering (using the Hodrick-Prescott filter).

Potential PMI was determined using a two-lag ARDL model; the number of lags was chosen based on the Schwarz criterion:

$$
P M I_{t}=b_{0}+\sum_{i=1}^{2} b_{i} P M I_{t-i}+\sum_{j=0}^{2} c_{j} G D P_{t-j}^{U S}+\gamma_{t}
$$

The model variables and their equilibrium paths are presented in the Appendix (Figures 4 and 5). 


\section{External sector BVAR model}

Section 3 provides a detailed description of the structure of the external sector BVAR model. The first part describes the general form of the BVAR model with its restrictions. The second part stipulates the procedure for selecting and finding BVAR hyperparameters. The third part describes the methodology for building scenario forecasts.

\subsection{Model structure}

The conventional VAR model for the $N$-dimensional vector of endogenous parameters $y_{t}$ and the $M$-dimensional vector of exogenous parameters $x_{t}$ can be conveyed as follows:

$$
\begin{gathered}
y_{t}=a_{0}+\sum_{i=1}^{p} A_{i} y_{t-i}+\sum_{j=0}^{q} B_{j} x_{t-j}+\epsilon_{t}, \\
\epsilon_{t} \sim N(0, \Sigma),
\end{gathered}
$$

where $A_{1}, \ldots, A_{p}-N \times N$ matrices of coefficients for the $p$ lags of endogenous variables; $B_{1}, \ldots, B_{p}-N \times M$ matrices of coefficients for the $q$ lags of exogenous variables; $a_{0}$ is the $N$-dimensional vector of constants; and $\Sigma$ is the covariance error matrix $\epsilon_{t}$.

In the specification of the BVAR model for the external sector, $N=46$, $M=1, q=1$, and $a_{0}=0$. The model also involves an additional restriction on the $B_{1}$ matrix implying that the exogenous variable 'Brent price' is only included in the equations with the movements of the growth rates of price indices. In other words, the corresponding coefficients of the $B_{1}$ matrix are equal to zero in all equations, except those for price indices. This decision was made because when the oil price was included in other equations in the course of scenario forecasting, the dynamics of real macro-variables became highly volatile. At the same time, the inclusion of the oil price in price equations significantly improves the predictive properties of the movements of price indices.

\subsection{Hyperparameters}

The parameters of the BVAR model are reduced using the Minnesota prior distribution proposed by Doan et al. (1984) and Litterman (1986). This distribution is based on the assumption that the movements of variables may be described as follows:

$$
y_{t}=a_{0}+\delta y_{t-1}+\epsilon_{t}
$$

This is equivalent to the reduction of the diagonal elements of the $A_{1}$ matrix to $\delta_{i}$, and the remaining elements in the matrices $A_{1}, \ldots, A_{p}$ to 0 . The following assumptions are also met. First, the larger is the number of a lag, the less 
important is the information it conveys. Second, the variable's own lags explain the variation better than the lags of other variables. These assumptions may be presented as follows:

$$
\mathbb{E}\left[\left(A_{k}\right)_{i j}\right]=\left\{\begin{array}{ll}
\delta_{i}, & j=i, k=1, \\
0, & \text { otherwise }
\end{array} \mathbb{V}\left[\left(A_{k}\right)_{i j}\right]=\left\{\begin{array}{c}
\left(\frac{\lambda}{k^{\mu}}\right)^{2}, \quad j=i \\
v\left(\frac{\lambda}{k^{\mu}} \frac{\sigma_{i}}{\sigma_{j}}\right)^{2}, \text { otherwise }
\end{array}\right.\right.
$$

The coefficients $A_{1}, \ldots, A_{p}$ are independent and are normally distributed, and the covariance matrix is diagonal $\Xi=\operatorname{diag}\left(\sigma_{1}^{2}, \ldots, \sigma_{\mathrm{N}}^{2}\right)$.

The hyperparameter $\lambda$ (regularisation parameter) controls the overall tightness of the prior distribution relative to model (4) and reflects the importance of the prior distribution relative to the information in the data series. If $\lambda=0$, the posterior distribution of the parameters coincides with the prior one, and the data do not impact the estimation. If $\lambda=\infty$, the posterior expectation coincides with the estimation using the ordinary least squares method (OLS).

$1 / k^{2 \mu}$ is the pace at which the prior variance decreases as the lag number increases. The cross-regularisation parameter $v \in[0 ; 1]$ adds extra tightness to the lags of other variables as compared to their own lags.

The values of the hyperparameters of the prior distribution and the number of lags are selected by searching all possible theoretical values using the Bayesian optimisation algorithm suggested by Mockus et al. (1978). A modern modification of this algorithm was described by Bull (2011). The main idea of the algorithm is to minimise the value of the loss function $f(x)$ with $x$ lying in a restricted space. The mean normalised root-mean-square error (MNRMSE) averaged over all forecasts is used as the function $f(x)$. The set of parameters $x$ consists of $p, \delta, \lambda, v, \mu$. Since it is rather complicated to derive the exact form of the function $f(x)$, we assume that $f(x)$ has the prior distribution $\pi$ that is described by the stationary Gaussian process. At each step $n$, the algorithm selects such a set of parameters $x_{n+1}$ that would maximise the value of the expected improvement function $E I$ :

$$
E I_{n}\left(x_{n+1} ; \pi\right)=\mathbb{E}\left[f\left(x_{n}\right)-f\left(x_{n+1}\right)\right]
$$

Table 2. Hyperparameter values

\begin{tabular}{ll} 
Parameter & Value \\
\hline$p$ & 3 \\
\hline$\delta$ & 0.32 \\
\hline$\lambda$ & 0.054 \\
\hline$v$ & 0.57 \\
\hline$\mu$ & 1 \\
\hline
\end{tabular}




\subsection{Scenario forecasts}

Scenario forecasts are generally built in VAR models using the algorithm described by Wagoner and Zha (1999). However, due to its high computational complexity, this algorithm is not applicable to large-size models with a long forecast horizon. In line with a study by Bańbura et al. (2015), the external sector BVAR model uses a modification of the algorithm based on the Kalman filter. This approach was first proposed by Clarida and Coyle (1984). Since the Kalman filter is implemented recursively, i.e. period by period, its computational complexity does not depend on a forecast horizon and, therefore, it may be employed in large-size VAR models.

Additionally, after the filtering, the Kalman smoothing algorithm is used, which was described in detail by Harvey (1990). The smoothing makes it possible to build a forecast that would take into account information over the entire forecast horizon at once. In other words, the forecast in the period $t$ generated as a result of the filtering of the first step is a mathematical expectation conditional on the information available in the period $t$. The same forecast in the period $t$ adjusted by the smoothing algorithm at the second step is a mathematical expectation conditional on all information available, including information after the period $t$.

In scenario forecasting, the model sets conditions for the path of policy rates and oil price movements. Moreover, since the model simultaneously uses GDP and the breakdown of GDP by component, forecasting involves linear restrictions that are additionally imposed on the paths in the following form:

$$
G D P_{i t}-\sum_{j=1}^{5} \text { Share }_{i j t} C_{i j t}=0 .
$$

\section{Forecasting performance of the model}

The forecasting capabilities of the external sector BVAR model were assessed at two stages: first, we analysed the forecast errors of the model occurring in an out-of-sample forecasting exercise; and at the second stage, the forecast errors of this model were compared against the forecast errors of possible simpler models.

\subsection{Error in out-of-sample forecasts}

The predictive performance of the external sector BVAR model was assessed by building out-of-sample forecasts. At the first stage, the model coefficients were estimated based on the sample from 1996Q2 to the quarter $Q-1$, where $Q \in$ [2010Q1 - 2019Q3]. Then, from the point $Q$ a forecast was built for $k$ quarters ahead, where $k$ sequentially takes values from 1 to 12 . Based on the forecasts generated for each variable $y_{i}$, the $M N R M S E^{k}$ was calculated as follows:

$$
R M S E_{Q}^{k}=\sqrt{\frac{\sum_{t=Q}^{Q+k}\left(y_{t}^{i}-\widehat{y_{t}^{i}}\right)^{2}}{k}},
$$




$$
\begin{gathered}
N R M S E_{Q}^{k}=\frac{R M S E_{Q}^{k}}{\delta_{y_{i}}}, \\
M N R M S E^{k}=\frac{\sum_{Q} N R M S E_{Q}^{k}}{39-k},
\end{gathered}
$$

where $R M S E_{Q}^{k}$ is the root mean squared error of the forecast issued in the period $Q$ for $k$ quarters ahead; $N R M S E_{Q}^{k}$ is the normalised root mean squared error of the forecast; $\delta_{y_{i}}$ is the standard deviation of the variable $y_{i}, M N R M S E^{k}$ is the mean normalised root mean squared error of the forecast for $k$ quarters averaged for all $Q$; and $39-k$ is the number of quarters based on which the forecast for $k$ quarters ahead was issued.

\begin{tabular}{|c|c|c|c|c|c|c|c|c|c|c|c|c|}
\hline US & 0.24 & 0.26 & 0.26 & 0.27 & 0.27 & 0.28 & 0.28 & 0.28 & 0.29 & 0.29 & 0.29 & 0.29 \\
\hline US consumption & 0.16 & 0.18 & 0.19 & 0.19 & 0.20 & 0.20 & 0.20 & 0.21 & 0.21 & 0.22 & 0.22 & 0.23 \\
\hline US investment & 0.54 & 0.58 & 0.60 & 0.61 & 0.61 & 0.61 & 0.61 & 0.62 & 0.61 & 0.61 & 0.61 & 0.60 \\
\hline & 31 & 0.33 & 0.33 & 0.33 & 0.33 & 0.33 & 0.33 & 0.33 & 0.33 & 0.33 & 0.33 & 0.33 \\
\hline rts & 29 & 0.34 & 0.35 & 0.35 & 0.35 & 0.35 & 0.35 & 0.35 & .35 & 35 & 0.35 & .35 \\
\hline US govern & 0.68 & 0.73 & 0.74 & 0.75 & 0.75 & 0.74 & 0.74 & 0.74 & 0.74 & 0.74 & 0.74 & 0.74 \\
\hline US PCE & 0.32 & 0.35 & 0.36 & 0.36 & 0.37 & 0.37 & 0.37 & 0.38 & 0.38 & 0.39 & 39 & 0.39 \\
\hline US core & 66 & 0.72 & 0.74 & 0.74 & 0.75 & 0.76 & 0.76 & 0.77 & 0.78 & 0.79 & .79 & .79 \\
\hline 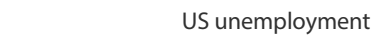 & 12 & 0.14 & 0.15 & 0.15 & 0.16 & .16 & 0.16 & 0.17 & .17 & 0.17 & .17 & .18 \\
\hline Euro & 0.15 & 0.17 & 0.17 & 0.17 & 0.17 & 0.17 & 0.18 & 0.18 & 0.18 & 0.18 & 0.18 & 0.18 \\
\hline Euro area & 0.35 & 0.40 & 0.42 & 0.43 & 0.44 & 0.45 & 0.45 & 0.45 & 0.45 & 0.45 & .45 & 0.45 \\
\hline & .85 & 0.93 & 0.93 & 0.95 & 0.96 & 0.96 & 0.97 & 0.98 & 0.98 & 0.99 & 1.00 & 02 \\
\hline & 42 & 0.48 & .49 & 0.51 & 0.52 & 0.53 & 0.53 & 0.54 & 0.54 & 0.55 & 0.55 & 0.56 \\
\hline ts & 0.73 & 0.76 & 0.76 & 0.77 & 0.78 & 0.79 & 0.80 & 0.81 & 0.81 & 0.81 & 0.81 & 0.81 \\
\hline government & 0.56 & 0.60 & 0.61 & 0.62 & 0.62 & 0.61 & 0.60 & 0.58 & 0.58 & 0.57 & 0.56 & 0.56 \\
\hline & 0.49 & 0.54 & 0.58 & 0.61 & 0.63 & 0.64 & 0.65 & 0.66 & 0.67 & 0.68 & 0.69 & 0.69 \\
\hline enar r r & 0.95 & 1.12 & 1.25 & 1.32 & 1.37 & 1.41 & 1.44 & 1.47 & 1.49 & 1.51 & 1.54 & 1.56 \\
\hline Euro area unempl & 0.46 & 0.52 & 0.56 & 0.59 & 0.63 & 0.65 & 0.67 & 0.68 & 0.69 & 0.70 & 0.70 & 0.70 \\
\hline & 0.09 & 0.10 & 0.11 & 0.11 & 0.11 & 0.12 & 0.12 & 0.11 & 0.11 & 0.11 & 0.11 & 0.12 \\
\hline China & 8 & 0.20 & 0.21 & 0.22 & 0.22 & 0.22 & 0.21 & 0.21 & 0.21 & 0.21 & 0.21 & 0.20 \\
\hline China & 0.21 & 0.25 & 0.26 & 0.27 & 0.27 & 0.28 & 0.28 & 0.27 & 0.28 & 0.28 & 0.28 & 0.28 \\
\hline China & 0.62 & 0.67 & 0.68 & 0.69 & 0.69 & 0.70 & 0.70 & 0.70 & 0.71 & 0.72 & 0.72 & 0.73 \\
\hline & 0.67 & 0.71 & 0.73 & 0.73 & 0.73 & 0.74 & 0.74 & 0.74 & 0.74 & 0.74 & 0.74 & 0.7 \\
\hline nment consumption & 0.49 & 0.54 & 0.58 & 0.61 & 0.63 & 0.66 & 0.69 & 0.71 & 0.72 & 0.73 & 0.74 & 0.7 \\
\hline China CPI & 0.39 & 0.45 & 0.46 & 0.48 & 0.47 & 0.47 & 0.47 & 0.47 & 0.47 & 0.47 & 0.48 & 0.48 \\
\hline China unemployment & 0.40 & 0.47 & 0.51 & 0.52 & 0.52 & 0.52 & 0.52 & 0.52 & 0.52 & 0.52 & 0.52 & 0.51 \\
\hline & & Q2 & Q3 & Q4 & Q5 & Q6 & Q7 & Q8 & Q9 & Q10 & Q11 & Q12 \\
\hline
\end{tabular}

Figure 1. Mean normalised root mean squared error for $k$ quarters $\left(M N R M S E^{k}\right)$

The $M N R M S E^{k}$ values obtained for all model variables are presented in Figure 1 . Since the values are normalised to the standard deviation, we may say that if $M N R M S E^{k}=1$, the model predicts in the same way as if the sample mean were used as the forecast. If $M N R M S E^{k}<1$, the model predicts better than the sample mean.

As shown by Figure 1, the model has satisfactory predictive capabilities for the main variables of interest: the mean value of MNRMSE in the table is below 0.3 for all the three countries, and the mean value of MNRMSE in the table for overall inflation is 0.4 for the USA, 0.5 for China and 0.6 for the euro area. The accuracy 
of the forecast of the GDP component breakdown is also adequate, with the mean value of MNRMSE in the table $<1$ for all components in all the three countries. The mean value of MNRMSE in the table for unemployment is 0.2 for the USA, and 0.5-0.6 for the euro area and China. The model builds the least accurate forecasts for core inflation in the euro area. For this reason, the path of core inflation is additionally adjusted in the MPD's forecast using auxiliary models and expert estimates. Figures 6 and 7 (see Appendix) provide diagrams with the predicted paths issued based on all quarters $Q$.

\subsection{Comparison of the external sector BVAR model with other models}

Additionally, the predictive performance of the BVAR model is compared with simpler models: an AR(1) model for each variable, three separate VAR models for each country, and a BVAR model for the three countries consisting of 12 key variables. These models were built in a detrended form. The model was also compared with a BVAR(46) model built for variables in levels without detrending. To compare the results, the MNRMSE was calculated for variables not in deviations, but in levels. The forecasts were generated conditionally on the path of the oil price and rates. Additionally, we calculated the values of MNRMSE for output gaps in the USA and the euro area restored from GDP growth rates. The results with the values of MNRMSE averaged for four and twelve quarters are presented in Table 3.

Table 3. MNRMSE averaged over the main variables of interest in different models

\begin{tabular}{|c|c|c|c|c|c|c|c|c|c|c|}
\hline & \multicolumn{2}{|l|}{$\operatorname{AR}(1)$} & \multicolumn{2}{|c|}{ Country VAR(5) } & \multicolumn{2}{|c|}{$\operatorname{BVAR}(12)$} & \multicolumn{2}{|c|}{$\operatorname{BVAR}(46)$} & \multicolumn{2}{|c|}{ Restored BVAR(46) } \\
\hline & $\begin{array}{l}\text { RMSE } \\
\text { (1 year) }\end{array}$ & $\begin{array}{l}\text { RMSE } \\
\text { (3 years) }\end{array}$ & $\begin{array}{l}\text { RMSE } \\
\text { (1 year) }\end{array}$ & $\begin{array}{l}\text { RMSE } \\
\text { (3 years) }\end{array}$ & $\begin{array}{l}\text { RMSE } \\
\text { (1 year) }\end{array}$ & $\begin{array}{l}\text { RMSE } \\
\text { (3 years) }\end{array}$ & $\begin{array}{l}\text { RMSE } \\
\text { (1 year) }\end{array}$ & $\begin{array}{l}\text { RMSE } \\
\text { (3 years) }\end{array}$ & $\begin{array}{l}\text { RMSE } \\
\text { (1 year) }\end{array}$ & $\begin{array}{l}\text { RMSE } \\
\text { (3 years) }\end{array}$ \\
\hline \multicolumn{11}{|c|}{ GDP growth, \% QoQ } \\
\hline USA & 0.25 & 0.27 & 0.29 & 0.32 & 0.26 & 0.28 & 0.25 & 0.27 & 0.58 & 0.61 \\
\hline Euro area & 0.14 & 0.15 & 0.17 & 0.18 & 0.15 & 0.17 & 0.15 & 0.16 & 0.49 & 0.53 \\
\hline China & 0.06 & 0.07 & 0.14 & 0.17 & 0.08 & 0.08 & 0.09 & 0.10 & 0.28 & 0.27 \\
\hline \multicolumn{11}{|c|}{ Output gap, $\%$ of potential GDP } \\
\hline USA & 0.23 & 0.39 & 0.23 & 0.38 & 0.23 & 0.39 & 0.21 & 0.32 & - & - \\
\hline Euro area & 0.17 & 0.34 & 0.21 & 0.38 & 0.18 & 0.37 & 0.17 & 0.30 & - & - \\
\hline \multicolumn{11}{|c|}{ Overall inflation, \% QoQ } \\
\hline USA & 0.65 & 0.72 & 0.44 & 0.46 & 0.42 & 0.46 & 0.35 & 0.37 & 0.37 & 0.43 \\
\hline Euro area & 0.86 & 0.97 & 0.63 & 0.70 & 0.69 & 0.78 & 0.56 & 0.63 & 0.54 & 0.62 \\
\hline China & 0.50 & 0.51 & 0.49 & 0.56 & 0.43 & 0.44 & 0.44 & 0.46 & 0.49 & 0.52 \\
\hline
\end{tabular}

As can be seen from Table 3, the main advantage of the BVAR(46) model is a higher accuracy of the forecasts of overall inflation in the USA, the euro area, 
and China. Over all time horizons, the accuracy of the overall inflation forecasts for the USA and the euro area generated by the BVAR(46) model is significantly higher compared to other models, while the accuracy of the inflation forecast for China based on BVAR(46) is comparable to the accuracy achieved by BVAR(12). As for the GDP forecast, the results of the AR(1), BVAR(12) and BVAR(46) models differ insignificantly for the USA and the euro area, while the forecast accuracy of these models is higher than that of VAR(5) models focused on individual countries. Although errors in the GDP forecasts are comparable, the BVAR(46) model generates the most accurate forecast of an output gap restored from GDP over a three-year horizon.

Table 3 also shows that the accuracy of a GDP growth forecast in the original detrended BVAR(46) model is twice better than the accuracy of BVAR(46) in the levels. This improvement is achieved by incorporating the economically justified path of potential GDP which the forecasts in the original model converge to. The detrended model and the model in levels do not differ significantly in terms of the accuracy of the overall inflation forecasts because a constant equal to target inflation was used as the equilibrium inflation rate.

\section{Using the model based on the example of the joint forecasting round in December 2019}

This section describes the procedure for employing the BVAR model and the results obtained by the example of the joint forecasting round carried out in December 2019. The results obtained are also compared with the IMF forecasts.

To build a scenario forecast based on the external sector BVAR model, it is necessary to set conditions for the oil price and nominal interest rates. The path of the oil price is set based on expert estimates and the results of the BVAR model for the oil price. The paths of interest rates are determined by expert judgement, depending on the assumptions of a particular scenario. In December 2019, the baseline scenario provided for a smooth convergence of the oil price to USD 55 per barrel over the course of 2020 and the maintenance of this level over 2021-2022. The USA was expected to keep the current level of the policy rate within the range of $1.5-1.75 \%$ until $2020 \mathrm{Q} 2$, reduce it by 0.25 percentage points for $2020 \mathrm{Q} 3$, and maintain the resulting rate range of $1.25-1.5 \%$ until the end of the forecast horizon. The euro area was expected to keep the current level of policy rates until the end of the forecast horizon.

Figure 2 compares the forecast generated by the external sector BVAR model for the main variables under the baseline scenario with the IMF forecast (International Monetary Fund, 2019). The IMF forecast provides for a slightly higher oil price: USD 60 per barrel in 2020 and USD 57 per barrel in 2021-2022.

The forecast based on the BVAR model suggests a stronger response of the economies of the USA and the euro area in 2020 to the existing trade policy 
Figure 2. Forecast of the external sector BVAR model in the joint forecasting round carried out in December 2019, compared to the IMF forecast
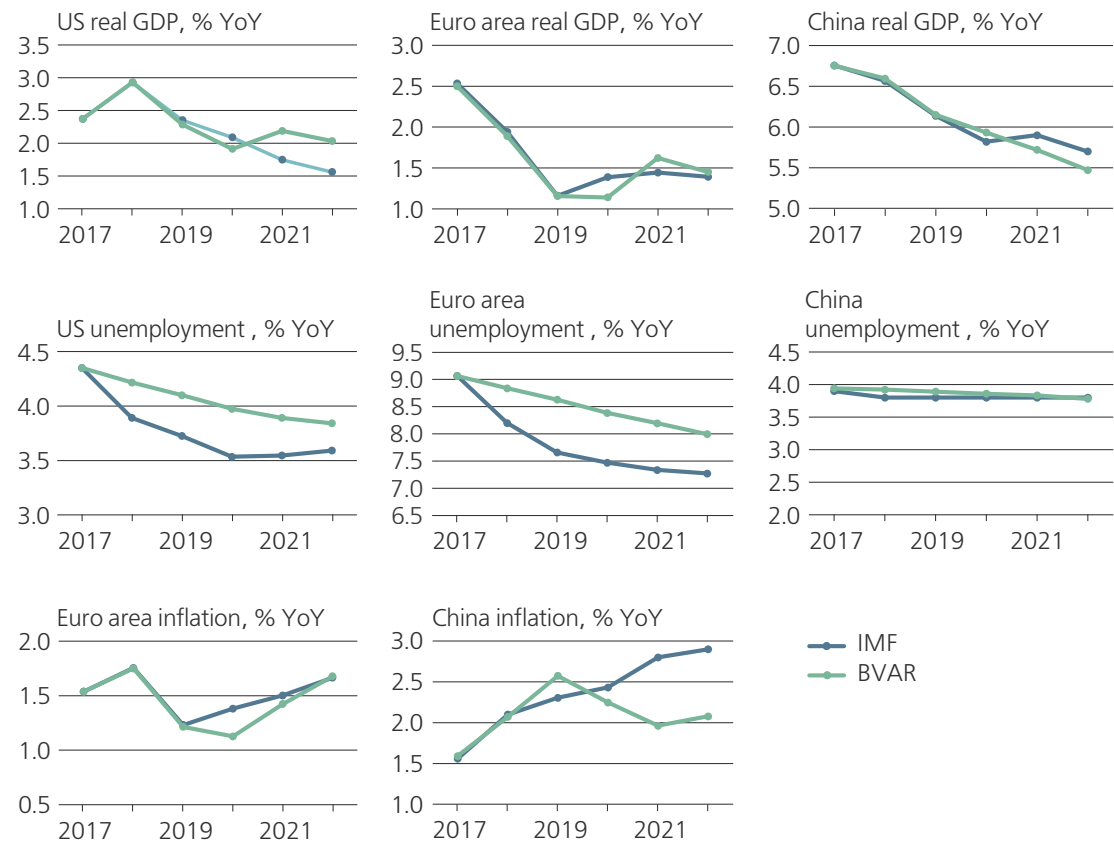

uncertainty. This is evidenced by a slightly lower GDP growth rate in 2020 in the BVAR forecast compared to the IMF forecast.

In the BVAR forecast, after the decline in 2020, the US and euro area economies recover rather quickly in 2021 and return to their potential growth rates in 2022 . It may be noted that the IMF forecast suggests a stronger slowdown in the US GDP growth at the end of the forecast horizon. According to official comments on the forecast, low growth rates in the USA in 2022 are not associated with the trade war as the two-year budget agreement and the reduction in the US Fed rate in 2019 offset the effect of trade uncertainty. A probable reason for the differences may be that the Bank of Russia's MPD and the IMF estimate the potential growth rates of the US GDP differently. The MPD estimates the US GDP growth in equilibrium at $2 \%$ YoY. This figure was obtained given the results of the multidimensional filter for estimating potential GDP, as well as the estimates by the European Commission (European Commission, 2019) and the OECD (OECD, 2019). The forecasts of China's GDP growth for 2020 are comparable. Nonetheless, BVAR suggests a slightly faster slowdown in the Chinese economy over the forecast horizon: 5.5\% YoY by 2022 against the IMF forecast of 5.7\% YoY in 2022 and 5.5\% YoY in 2023.

The unemployment forecast generated by the BVAR model is comparable with the IMF forecasts. The discrepancies in the forecasts of overall inflation result from the differences in GDP growth rates and oil prices. 


\section{Conclusion}

The multi-country BVAR model for the external sector described herein is used by the MPD to build coordinated scenario forecasts of the main macroeconomic indicators of the USA, the euro area, and China. The forecasts in the model are generated conditionally on the pre-determined paths of the US dollar index, the oil price, and policy rates. The key variables of interest are GDP and overall inflation. The forecasts obtained are used as scenario assumptions for the external sector in forecasting models for Russia.

In addition to the key variables, the external sector BVAR model also employs a wide range of macroeconomic and financial variables, which generates a broader picture of what is happening in the world and significantly enhances the forecast of overall inflation compared to models comprising only the key variables. The simultaneous modelling of the three economies makes it possible to factor in the structure of multicountry interactions, which increases the accuracy of the forecast for the main variables compared to separate VAR models. The detrended design of the model ensures the convergence of the predicted paths to potential values that are adjusted depending on the current situation and scenario assumptions. As a result, the accuracy of the GDP forecast in the model in the detrended form is higher compared to the restored form.

There is also room for further improvement of the model. It may be worth testing alternative approaches to setting prior distributions, which would take into account the difference between the intra-country and multi-country interactions of variables, but for now we leave this for future research.

\section{Appendix is available at http://rjmf.econs.online/en; dx.doi.org/10.31477/rjmf.202004.98}

\section{References}

Angelini, E., Lalik, M., Lenza, M. and Paredes, J. (2019). Mind the Gap: A MultiCountry BVAR Benchmark for the Eurosystem Projections. International Journal of Forecasting, 35(4), pp. 1658-1668. doi: 10.1016/j.ijforecast.2018.12.004

Bańbura, M., Giannone, D. and Lenza, M. (2015). Conditional Forecasts and Scenario Analysis with Vector Autoregressions for Large Cross-Sections. International Journal of Forecasting, 31(3), pp. 739-756. doi: 10.1016/j.ijforecast.2014.08.013

Bańbura, M., Giannone, D. and Reichlin, L. (2010). Large Bayesian Vector Auto Regressions. Journal of Applied Econometrics, 25(1), pp. 71-92. doi: 10.1002/jae.1137

Benes, J., Clinton, K., Garcia-Saltos, R., Johnson, M., Laxton, D., Manchev P. and Matheson, T. (2010). Estimating Potential Output with a Multivariate Filter. IMF Working Papers, N 285.

Bull, A. D. (2011). Convergence Rates of Efficient Global Optimization Algorithms. Journal of Machine Learning Research, 12(88), pp. 2879-2904.

Capolongo, A. and Pacella, C. (2019). Forecasting Inflation in the Euro Area: Countries Matter! Bank of Italy Temi di Discussione (Working Papers), N 1224. 
Carriero, A., Clark, T. E. and Marcellino, M. (2015). Bayesian VARs: Specification Choices and Forecast Accuracy. Journal of Applied Econometrics, 30(1), pp. 46-73. doi: 10.1002/jae.2315

Christiano, L. J., Eichenbaum, M. and Evans, C. L. (1999). Monetary Policy Shocks: What Have We Learned and to What End? In: J. B. Taylor and M. Woodford, eds. Handbook of Macroeconomics, Vol. 1(A), pp. 65-148. doi: 10.1016/S1574-0048(99)01005-8

Clarida, R. H. and Coyle, D. (1984). Conditional Projection by Means of Kalman Filtering. Cowles Foundation Discussion Papers, N 702.

Del Negro, M. and Schorfheide, F. (2011). Bayesian Macroeconometrics. In: J. Geweke, G. Koop, and H. van Dijk, eds. The Oxford Handbook of Bayesian Econometrics. Oxford: Oxford University Press, pp. 293-289. doi: 10.1093/oxfordhb/9780199559084.013.0008

Di Mauro, F. and Pesaran, M. H., eds. (2013). The GVAR Handbook: Structure and Applications of a Macro Model of the Global Economy for Policy Analysis. Oxford: Oxford University Press. doi: 10.1093/acprof:oso/9780199670086.003.0001

Doan, T., Litterman, R. and Sims, C. (1984). Forecasting and Conditional Projection Using Realistic Prior Distributions. Econometric Reviews, 3(1). pp. 1-100. doi: 10.1080/07474938408800053

Domit, S., Monti, F. and Sokol, A. (2016). A Bayesian VAR Benchmark for COMPASS. Bank of England Staff Working Paper, N 583.

European Commission (2019). European Economic Forecast: Autumn 2019. European Economy Institutional Paper, N 115.

Harvey, A. C. (1990). Forecasting, Structural Time Series Models and the Kalman Filter. Cambridge University Press.

Holston, K., Laubach, T. and Williams, J. C. (2017). Measuring the Natural Rate of Interest: International Trends and Determinants. Journal of International Economics, 108, pp. S59-S75. doi: 10.1016/j.jinteco.2017.01.004

International Monetary Fund (2019). World Economic Outlook, October 2019: Global Manufacturing Downturn, Rising Trade Barriers. Washington, DC: International Monetary Fund, October.

Lenza, M. and Slacalek, J. (2018). How Does Monetary Policy Affect Income and Wealth Inequality? Evidence from Quantitative Easing in the Euro Area. European Central Bank Working Paper Series, N 2190.

Litterman, R. B. (1986). Forecasting with Bayesian Vector Autoregressions - Five Years of Experience. Journal of Business and Economic Statistics, 4(1), pp. 25-38. doi: 10.1080/07350015.1986.10509491

Mandler, M., Scharnagl, M. and Volz, U. (2016). Heterogeneity in Euro-Area Monetary Policy Transmission: Results from a Large Multi-Country BVAR Model. Deutsche Bundesbank Discussion Paper, N3.

Mockus, J., Tiešis, V. and Žilinskas, A. (1978). The Application of Bayesian Methods for Seeking the Extremum. In: C. W. Dixon and G. P. Szegó, eds. Towards Global Optimization, Vol. 2. Amsterdam: North-Holland, pp. 117-129.

OECD (2019). OECD Economic Outlook, Vol. 2019(2), N 106. doi: 10.1787/4c90c873-en

Pesaran, M. H., Schuermann, T. and Weiner, S. M. (2004). Modeling Regional Interdependencies Using a Global Error-Correcting Macroeconometric Model. Journal of Business and Economic Statistics, 22(2), pp. 129-162.

Waggoner, D. F. and Zha, T. (1999). Conditional Forecasts in Dynamic Multivariate Models. Review of Economics and Statistics, 81(4), pp. 639-651. 